\title{
Kajian Lokasi Rawan Bencana Banjir Pada Daerah Aliran Sungai (DAS) Walanae Kecamatan Dua Boccoe Kabupaten \\ Bone
}

\author{
Study of Flood Prone Locations in the Walanae River Basin, Dua Boccoe District, Bone \\ Regency
}

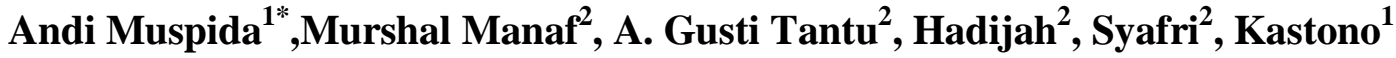 \\ *Email: andimuspida63@gmail.com \\ ${ }^{1}$ Program Doktoral Perencanaan Wilayah dan Kota, Program Pascasarjana, Universitas Bosowa \\ ${ }^{2}$ Program Studi Perencanaan Wilayah dan Kota, Program Pascasarjana, Universitas Bosowa
}

Diterima: 12 Mei 2021 / Disetujui: 02 Agustus 2021

\begin{abstract}
ABSTRAK
Bencana Banjir yang sering melanda Kabupaten Bone khususnya Kecamatan Dua Boccoe bukan hal baru. Dalam 20 tahun terakhir, Kecamatan ini sudah identik dengan kawasan banjir yang di sebabkan oleh curah hujan yang tinggi sehingga DAS Walanae meluap. Penelitian yang dilakukan bersifat deskriptif kualitatif atau penelitian terapan. Penelitian kualitatif merupakan penelitian non matematis dengan proses menghasilkan data-data dari hasil temuan berupa Observasi Lapangan. Analisis yang digunakan dalam penelitian yaitu analisis deskriptif kualitatif dengan menggunakan pendekatan Overlay (Superimpose). Dari hasil analisis data diketahui yang sangat berpotensi banjir ada 8 kelurahan/desa, yang meliputi Kelurahan Unyi, Desa Uloe, Desa Pekkasalo, Desa Kampoti, Desa Tocina, Desa Tawaroe, Desa Solo, dan Desa Matajang. Dengan seluas $131 \mathrm{~km}^{2}$, dan tinggi genangan eksisting $\pm 100-200 \mathrm{~cm}$ den periode genangan 10 jam menyebabkan Kecamatan Dua Boccoe sangat berpotensi terkena banjir.
\end{abstract}

Kata Kunci : Kerawanan Banjir, DAS, Walanae, Superimpose, Bone

\section{ABSTRACT}

Floods is one of disaster that often hit Bone Regency, especially Dua Boccoe Subdistrict. In the last 20 years, flood that happened in this sub-district caused by high rainfall so that the Walanae watershed overflows. The research conducted is descriptive qualitative or applied research. Qualitative research is a non-mathematical research with the process of generating data from the findings in the form of field observations. The analysis used in this research is qualitative descriptive analysis using the Overlay (Superimpose) approach. From the results of data analysis, it is known that there are 8 sub-districts/villages with high potential for flooding, which include Unyi Village, Uloe Village, Pekkasalo Village, Kampoti Village, Tocina Village, Tawaroe Village, Solo Village, and Matajang Village. With an area of 131 $\mathrm{km} 2$, and an existing inundation height of $\pm 100-200 \mathrm{~cm}$ with an inundation period of 10 hours, Dua Boccoe District is very potentially affected by flooding.

Keywords : Flood Vulnerability, Walanae Watershed, Superimpose, Bone

This work is licensed under Creative Commons Attribution License 4.0 CC-BY International license

\section{A. PENDAHULUAN}

Bencana Banjir adalah fenomena alam yang terjadi di kawasan yang banyak dialiri oleh aliran sungai. Banjir adalah aliran air yang relatif tinggi dan tidak tertampung oleh alur sungai atau saluran (Suparta, 2004). Intensitasnya pada suatu tempat maupun jumlah lokasi 
kejadian dalam setahun yaitu sekitar $40 \%$ di antara bencana alam yang lain. Bahkan pada tempat- tempat tertentu, banjir merupakan rutinitas tahunan. Lokasi kejadiannya bisa perkotaan atau pedesaan, negara sedang berkembang atau negara maju sekalipun (Suherlan, 2001).

Menurut Kementrian PU bahwa banjir adalah aliran air di permukaan tanah (surface water) yang relatif tinggi dan tidak dapat ditampung oleh saluran drainase atau sungai, sehingga melimpah kekanan dan kiri serta menimbulkan genangan/aliran dalam jumlah melebihi normal dan mengakibatkan kerugian pada manusia (Kementerian PU, 2003). Banjir adalah aliran/genangan air yang menimbulkan kerugian ekonomi atau bahkan menyebabkan kehilangan nyawa (Asdak, 2004).

Bencana banjir merupakan fenomena alam, yang terjadi karena dipicu oleh proses alamiah dan aktivitas manusia yang tidak terkendali dalam mengeksploitasi alam. Proses alamiah sangat tergantung pada kondisi curah hujan, tata air tanah (geohidrologi), struktur geologi, jenis batuan, geomorfologi, dan topografi lahan. Sedangkan aktivitas manusia terkait dengan perilaku dalam mengeksploitasi alam untuk kesejahteraan manusia, sehingga akan cenderung merusak lingkungan, apabila dilakukan dengan intensitas tinggi dan kurang terkendali (Kodoatie \& Sugiyanto, 2002). Bencana banjir dapat terjadi setiap saat dan sering mengakibatkan kerugian jiwa dan harta benda. Kejadian banjir tidak dapat dicegah, namun hanya dapat dikendalikan dan dikurangi dampak kerugian yang diakibatkannya.

Banyaknya kejadian bencana banjir menunjukkan bahwa persoalan banjir merupakan persoalan serius dan memerlukan langkah-langkah produktif guna mereduksi bahaya banjir. Kejadian banjir baik skala besar maupun skala kecil seharusnya dijadikan bahan pembelajaran. Untuk mengatasi persoalan banjir sebagaimana kasus-kasus di atas pemerintah baik pusat dan daerah harus berperanlebih, tidak sekedar penyelesaian masalah dan korban pasca banjir, tetapi upaya- upaya preventif agar intensitas banjir dapat dikurangi melalui berbagai kebijakan yang berkaitan dengan sumberdaya lahan/wilayah (Kementerian PU, 2005).

Berbagai masalah yang berkaitan dengan banjir dan banyak aplikasi lainnya membuktikan bahwa masalah ini dapat diselesaikan melalui studi perencanaan 
dan proyek detail tentang daerah rawan banjir. Menentukan wilayah rawan banjir sangat penting bagi pengambil keputusan untuk perencanaan atau pengelolaan kegiatan (Yalcin \& Akyure. 2004). Langkah - langkah perencanaan penggunaan lahan yang tepat adalah cara yang paling efektif untuk mengurangi risiko banjir dan kerusakan. Untuk itu perencanaan penggunaan lahan yang tepat dan sesuai dengan mempertimbangkan aspek bencana khususnya banjir penting untuk dilakukan dan terintegrasi dalam rencana tata ruang.

Kecamatan Dua Boccoe merupakan kecamatan di Kabupaten Bone yang sering dilanda banjir selama 20 tahun terakhir (BPBD Kabupaten Bone, 2016). Kecamatan yang ada di utara Kabupaten Bone, yang berbatasan di bagian utara Kabupaten Wajo, dan empat kecamatan yang bagian barat yaitu Kecamatan Ajangale dan Kecamatan Amali, sebelah selatan berbatasan dengan Kecamatan Tellusiattingnge, dan sebelah timur berbatasan dengan Kecamatan Cenrana. Dengan luas Kecamatan Dua Boccoe yaitu $14,490 \mathrm{~km}^{2}$, yang terdiri dari 22 Kelurahan/Desa. Disamping karena keadaan geografis kecamatan ini berada pada daerah yang rendah sehingga seringkali dilanda banjir kiriman dari
Kabupaten Soppeng dan Kabupaten Wajo yang berada pada posisi geografis sedikit lebih tinggi. Jika curah hujan tinggi maka otomatis sebagian wilayah kecamatan ini terendam banjir. Di sebelah Barat Kelurahan Unyi, Desa Uloe, dan Desa Tawaroe terdapat Danau Ujung berupa rawa-rawa dan Sungai Unyi di sebelah Timur yang membelah Desa Uloe dan Kelurahan Unyi. Sungai Unyi bermuara di Daerah Aliran Sungai (DAS) Walanae. Jika desa-desa yang berada di kawasan Gunung Mampu (Desa Cabbeng) terdapat curah hujan yang tinggi maka Sungai Unyi menjadi meluap. Dalam kondisi seperti ini maka air Bah Sungai Unyi tertahan di Desa Uloe karena DAS Walanae tidak mampu lagi menampung yang juga mendapat kiriman banjir dari Soppeng dan Wajo.

DAS Walanae terdiri dari 7 (tujuh) Sub DAS, yaitu; Batu, Puteh, Malanroe, Mario, Minraleng, Sanrego, dan Walanae. Dari ketujuh Sub DAS tersebut Sebagian besar memiliki bentuk DAS memanjang, hanya Sub DAS Malanroe dan Walanae Hilir yang memiliki bentuk radial. Sedangkan untuk pola aliran didominasi pola dendritik medium (sedang) dengan kerapatan aliran terendah $72 \mathrm{~m} / \mathrm{ha}$ (walanae hilir) dan tertinggi $318,74 \mathrm{~m} / \mathrm{ha}$ (walanae tengah). 
Dengan debit sungai rata-rata di hulu $243,50 \mathrm{~m}^{3} /$ detik dan hilir $91,87 \mathrm{~m}^{3} /$ detik (BPBD Kabupaten Bone, 2016).

Melihat kronologis kejadian bencana banjir tersebut, banjir di Kabupaten Bone khususnya Kecamatan Dua Boccoe disebabkan oleh 3 (tiga) faktor Menurut Badan Penanggulangan Bencana Daerah (BPBD) Kabupaten Bone, yaitu Curah hujan yang tinggi, Banjir kiriman, dan Pendangkalan DAS Walanae. Sungai Walanae yang melintasi wilayah Kabupaten Bone perlu dinormalisasi khususnya wilayah Sungai Cenranae hingga ke Teluk Bone termasuk revitalisasi rawa-rawa kecil sepanjang kiri dan kanan daerah aliran sungai. Jika hal ini dilakukan maka dapat meminimalisir banjir dan tingkat erosi di sepanjang Daerah Aliran Sungai Walanae.

\section{B. METODE PENELITIAN}

Penelitian ini bersifat deskriptif kualitatif atau penelitian terapan yang di dalamnya mencakup penelitian survey, yaitu penelitian yang bertujuan untuk menggambarkan tingkat kerawanan banjir di Sub DAS Walanae Kecamatan Dua Boccoe Kabupaten Bone yang terjadi saat ini dan kemungkinan terjadinya dimasa akan datang. Peneliti mengambil lokasi studi sebagai obyek penelitian yaitu karena di Kecamatan Dua Boccoe merupakan daerah yang sering terjadi bencana banjir secara periodik yang biasanya diakibatkan oleh meluapnya Sub DAS Walanae serta kebiasaan buruk masyarakat yang sering menjadi penyebab banjir terjadi pada lokasi penelitian.

Adapun jenis data yang terkumpul terbagi atas dua jenis, yaitu data primer dan sekunder.

1. Data primer yaitu data yang diperoleh dari sumber asli atau sumber pertama melalui Observasi Langsung untuk mendapatkan informasi ataupun data yang dibutuhkan. Data primer yang dibutuhkan antara lain:

a. Data penggunaan lahan/eksisting

b. Kondisi ketinggian dan penyebab banjir dari hasil observasi masyarakat.

2. Data sekunder yaitu data yang diperoleh atau dikumpulkan dengan mengunjungi tempat atau instansi terkait dengan penelitian. Data sekunder ini dapat berupa literatur, dokumen, serta laporanlaporan yang berkaitan dengan penelitian yang dilakukan. Data sekunder yang dibutuhkan antara lain:

a. Data aspek fisik dasar meliputi: topografi dan kemiringan 
lereng, jenis tanah, kondisi

curah hujan, dan penggunaan

lahan.

b. Karakteristik banjir

c. Data Demografi Penduduk Kecamatan Dua Boccoe.

d. Peta-peta yang mendukung penelitian

Data yang terkumpul selanjutnya akan dianalisis melalui dua metode, yaitu:

1. Analisis kondisi fisik dasar, digunakan untuk menganalisa data dengan menggambarkan keadaan kondisi fisik alam yang terjadi di wilayah penelitian untuk selanjutnya diklasifikasi berdasarkan tujuan yang dicapai. Analisis kondisi fisik alam wilayah penelitian, meliputi analisis topografi dan kemiringan lereng, jenis tanah, kondisi curah hujan

2. Analisis superimpose ini digunakan untuk menentukan daerah rawan banjir dengan didasarkan pada beberapa aspek, antara lain kemiringan lereng, klasifikasi infiltrasi tanah, intensitas curah hujan dan pola penggunaan lahan pada suatu wilayah yang didasarkan pada pengharkatan dan pembobotan, adapun prosedur pemberian harkat dan bobot mengacu pada penelitian-penelitian sebelumnya serta pedoman Kementerian PU.

3. Analisis deskriptif kualitatif akan menguraikan secara jelas dampak yang telah ditimbulkan akibat bencana banjir yang ada di Kecamatan Dua Boccoe dari hasil observasi lapangan. Analisis ini juga digunakan untuk menganalisa data-data dengan menggambarkan keadaan wilayah pengamatan sesuai dari data yang diperoleh, adapun analisis deskriptif kualitatif digunakan untuk menganalisa penggunaan lahan dan kondisi fisik seperti topografi, kemiringan lereng dan hidrologi serta karakteristik banjir. Analisis ini juga di gunakan untuk penentuan arahan mitigasi bencana banjir yang ada di Kecamatan Dua Boccoe Kabupaten Bone.

\section{HASIL DAN PEMBAHASAN}

\section{Kondisi Fisik Wilayah}

\section{a. Topografi}

Bentuk hasil data kontur dan pengamatan di lapangan, kondisi topografi Kecamatan Dua Boccoe merupakan daerah dataran rendah dengan ketinggian sekitar <200 meter dari permukaan air laut (mdpl), kemiringan lereng $0-15 \%$, 
dengan kondisi topografi yang relative datar, menyebabkan Kecamatan Dua Boccoe rentan terhadap terjadinya genangan. Topografi yang rendah merupakan salah satu penyebab terjadinya banjir, karena air limpasan akan menuju ke tempat yang lebih rendah sebagaimana sifat air.

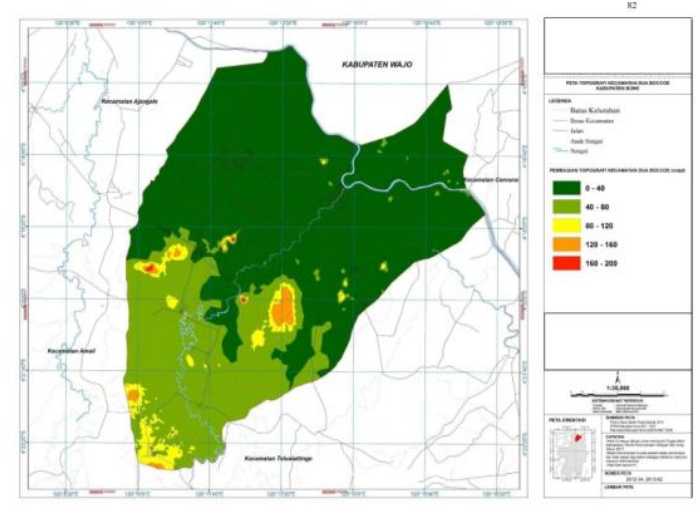

Gambar 1. Peta Zonasi Topografi Kecamatan Dua Boccoe

\section{b. Geologi dan Struktur Tanah}

Kondisi geologi Kecamatan Dua Boccoe meliputi Jenis tanah yang ada dibagian permukaan Kecamatan Dua Boccoe yaitu jenis tanah Aluvial. Jenis tanah yang ada di Kecamatan Dua Boccoe merupakan jenis tanah yang sangat padat dan sangat susah untuk menyerap air sampai kelapisan yang ada dibawahnya. Hal ini menyebabkan air yang mengalir atau genangan air yang ada dipermukaan tanah hanya sedikit yang mampu diserap. Kepadatan tanah tersebut turut mempengaruhi tingkat genangan.

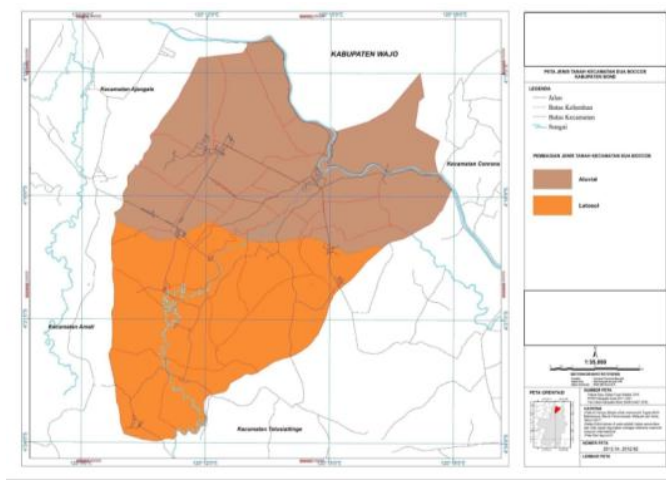

Gambar 2. Peta Zonasi Jenis Tanah Kecamatan Dua Boccoe

Kecamatan Dua Boccoe mempunyai kondisi geologi yang disusun oleh batuan sedimen dan vulkanik sebagai hasil pembentukan material yang berasal dari Gunung Latimojong. Jenis batuan yang ada di Kecamatan Dua Boccoe sangat berpengaruh dalam meningkatkan genangan air diwilayah-wilayah cekungan, endapan alluvial pasir dan sungai yang terdiri atas breksi dan konglomerat akan menyebabkan sedimentasi yang cukup tinggi dan dapat meperdangkal aliran sungai Walanae.

\section{c. Klimatologi}

Keadaan Iklim Kecamatan Dua Boccoe berupa iklim tropis dengan dua musim yaitu yaitu musim kemarau dan musim hujan. Kondisi curah hujan ratarata pertahun $2000 \mathrm{~mm}-3000 \mathrm{~mm}$, curah hujan tertinggi terjadi pada bulan Desember - Februari. Banjir juga dipengaruhi oleh kondisi curah hujan pada wilayah yang berada di sekitar 
Kecamatan Dua Boccoe, seperti Kabupaten Wajo dan Kabupaten Soppeng. Pada daerah penelitian memiliki kondisi curah hujan yang cukup tinggi pada bulan Desember - Februari hingga Mei - Juli sehingga perlu diwaspadai akan terjadinya bencana banjir pada bulan tersebut.

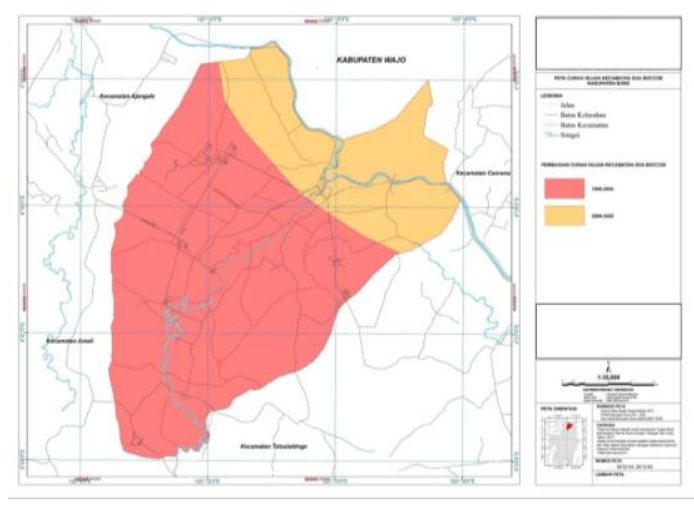

Gambar 3. Peta Zonasi Curah Hujan Kecamatan Dua Boccoe

\section{d. Hidrologi dan Sumber Daya Air}

Kondisi hidrologi di Kecamatan Dua Boccoe dengan air permukaan berasal dari DAS Walanae dengan panjang $15.763 \mathrm{Km}$, dan sungai Unyi serta adanya rawa- rawa pada beberapa desa yang sifat genangannya terjadi secara permanen dan periodik. Adapun pola aliran sungai DAS walanae yaitu masuk dalam tipe corak bulu burung, disebut bulu burung karena bentuk aliran anak sungainya menyerupai ruas-ruas tulang dari bulu burung. Anak-anak sungai langsung mengalir ke sungai utama. Luapan air yang berasal dari sungai yang terjadi setiap hujan dengan intesitas sedang-tinggi menyebakan area-area Kecamatan Dua Boccoe mengalami Genangan yang cukup tinggi.

Keberadaan rawa-rawa di Kecamatan Dua Boccoe dengan luas $2420.684 \mathrm{Ha}$ yang berfungsi sebagai cathment area cukup memberikan manfaat sebagai area yang akan menampung limpasan air hujan dan luapan air sungai sehingga keberadaannya sangat penting dan harus dipertahan. Apabila rawa-rawa tersebut tidak ada maka limpasan air hujan akan langsung tergenang area permukiman atau kawasan terbangun yang ada di Kecamatan Dua Boccoe.

\section{e. Penggunaan Lahan}

Penggunaan lahan (land use) di Kecamatan Dua Boccoe mengalami perubahan setiap tahun. Hal ini dipengaruhi oleh aktivitas dan pertumbuhan jumlah penduduk yang mendiami kawasan tersebut. Pemanfaatan lahan di Kecamatan Dua Boccoe terdiri dari Pemukiman (2,8\%), Sawah (35,1\%), Kebun Campuran (46,9\%), Rawa $(15,2 \%)$, dan Lapangan $(0,1 \%)$.

Meningkatnya jumlah penduduk akan diikuti oleh semakin besarnya kebutuhan lahan untuk permukiman. 
Dengan adanya perubahan penggunaan lahan dari lahan terbuka menjadi lahan terbangun untuk memenuhi kebutuhan penduduk tersebut, akan berimbas pada semakin berkurangnya area resapan air (cathment area) sehingga menimbulkan peningkatan jumlah limpasa air hujan dan semakin mempertinggi genangan yang terjadi.

Penggunaan lahan di Kecamatan

Dua Boccoe beragam. Kondisi ini menjadikan Kecamatan Dua Boccoe relatif padat dan cukup sesak sehingga perlu adanya pengendalian pemanfaatan ruang, khususnya di sekitar lokasi yang memiliki tingkat kepadatan bangunan yang cukup tinggi serta perlu adanya regulasi yang jelas dalam pemanfaatan lahan, khususnya lokasi-lokasi yang yang memiliki ruang-ruang terbuka untuk menjaga Kecamatan Dua Boccoe tetap memiliki Ruang terbuka yang berfungsi sebagai area tangkapan air maupun area resapan air.

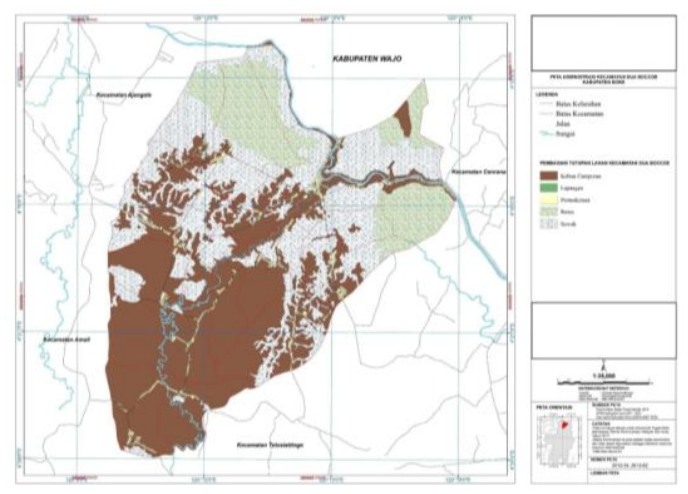

Gambar 4. Peta Zonasi Tutupan Lahan Kecamatan Dua Boccoe

\section{Analisis Superimpose}

Analisis Superimpose merupakan salah satu alat analisis yang digunakan untuk mengetahui tingkat kerawanan banjir di Kecamatan Dua Boccoe Kabupaten Bone yang terdiri dari 22 Kelurahan/Desa dengan menggunakan data kondisi fisik dasar yang ada pada wilayah tersebut, yang mana data tersebut terdiri dari Intensitas Curah Hujan, Kemiringan Lereng, Infiltrasi Tanah, dan Tata Guna Lahan. Dari semua data tersebut kemudia diolah dengan menggunakan metode overlay dengan menggunakan software ArcGis.

Dari hasil analisis tersebut, maka diperoleh klasifikasi tingkat kerawanan banjir dengan hasil skoring nilai terendah yaitu 36 dan nilai hasil skoring tertinggi 65. Klasifikasi tingkat kerawanan banjir tersebut didapatkan dengan rumus:

$$
K_{i}=\frac{65-36}{5}=5,8
$$

Berdasarkan hasil perhitungan kelas interval kerawanan banjir maka diperoleh bahwa interval kelas kerawanan banjir adalah 5, maka diketahui bahwa:
a. Skor tidak rawan $=36-40$
b. Skor kurang rawan $=41-45$
c. Skor agak rawan $=46-50$
d. Skor rawan $=51-55$
e. Skor sangat rawan $=>56$ 
Tabel 1. Kelas Interval Bencana Banjir Kecamatan Dua Boccoe dari Proses Overlay

\begin{tabular}{llcrr}
\hline No & Tingkat Kerawanan & Skor Nilai & Luas & Presentase \\
\hline & Sangat Rawan & $>56$ & 131.1 & 16.6 \\
& Rawan & $51-55$ & 234.4 & 29.8 \\
Agak Rawan & $46-50$ & 160.0 & 20.3 \\
& Kurang Rawan & $41-45$ & 123.3 & 15.6 \\
& Tidak Rawan & $36-40$ & 139.0 & 17.6 \\
\hline
\end{tabular}

Berdasarkan kelas interval kerawanan banjir, maka diperoleh 5 klasifikasi tingkat kerawanan bencana banjir di Kecamatan Dua Boccoe, seperti pada tabel dibawah.

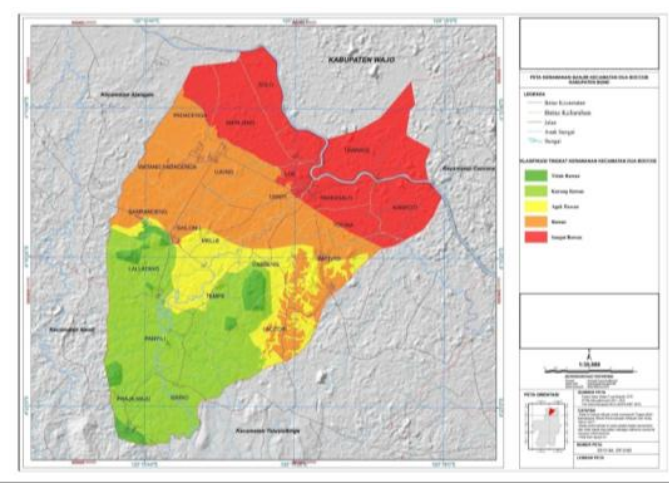

Gambar 5. Peta Klasifikasi Tingkat Kerawanan Bencana Banjir Kecamatan Dua Boccoe

Berdasarkan hasil analisis dengan menggunakan metode overlay pada ArcGIS, maka dapat dilihat pada Gambar 5 wilayah banjir dengan kondisi tingkat kerawanan banjir rendah (tidak rawan) mempunyai luasan $\pm 139.0 \mathrm{Km}^{2}$ atau $17,6 \%$ dari luas wilayah Kecamatan Dua Boccoe. Sedangkan tingkat kerawanan tinggi (sangat rawan) mempunyai luasan \pm $131.1 \mathrm{Km}^{2}$ atau sekitar 16,6 \% dari luas wilayah Kecamatan Dua Boccoe Kabupaten Bone, yang terdiri dari
Kelurahan Unyi, Desa Uloe, Desa Pakkasalo, Desa Kampoti, Desa Tocina, Desa Tawaroe, Desa Solo, dan Desa Matajang.

\section{KESIMPULAN DAN SARAN}

Hasil penelitian dapat disimpulkan bahwa tingkat kerawanan banjir di Kecamatan Dua Boccoe diklasifikasikan menjadi 5 kelas kerawanan yaitu, Sangat Rawan, Rawan, Agak Rawan, Kurang Rawan, dan Tidak Rawan. Wilayah dengan tingkat kerawanan Tidak Rawan seluas $139.0 \quad \mathrm{Km}^{2} \quad$ (17.6\%) yang meliputi sebagian wilayah Desa Lallatang, Desa Tempe, Desa Praja Maju, dan Desa Panyili. Wilayah dengan tingkat kerawanan Kurang Rawan seluas $123.3 \mathrm{Km}^{2} \quad(15,6 \%)$ yang berada di Desa Lallatang, Desa Panyili, Desa Tempe, Desa Mario, dan Desa Praja Maju. Wilayah dengan tingkat kerawanan Agak Rawan seluas $160.0 \quad \mathrm{Km}^{2} \quad(20,3 \%)$ yang meliputi sebagian wilayah Desa Sanrangeng, Desa Melle, Desa Cabbeng, Desa Laccori, dan Desa 
Pattiro. Wilayah dengan tingkat Rawan seluas 234.4 (29,8\%) yang meliputi Desa Padacenga, Desa Watang Padacenga, Desa Sanrangeng, Desa Ujung, Desa Sailong, sebagian Kelurahan Unyi, dan Desa Tocina. Wilayah dengan tingkat kerawanan Sangat Rawan seluas $131 \mathrm{Km}^{2}$ $(16,6 \%)$ yang meliputi Kelurahan Unyi, Desa Uloe, Desa Pekkasalo, Desa Kampoti, Desa Tocina, Desa Tawaroe, Desa Solo, dan Desa Matajang.

$$
\text { Banjir di Kecamatan Dua }
$$

Boccoe disebabkan oleh faktor internal (Topografi, Prasarana Drainase, Kepadatan Bangunan, dan Tata Guna Lahan,dll) dan faktor eksternal (Topografi, dan Bajir Kiriman). Pada umumnya banjir yang terjadi di lokasi penelitian disebabkan oleh faktor eksternal.

\section{DAFTAR PUSTAKA}

Suparta. W. 2004. Kajian Banjir Kota Denpasar Study Kasus Saluran Drainase Sistem IV Kota Denpasar, Denpasar; Program Studi Magister Ilmu Lingkungan Program Pasca Sarjana, Universitas Udayana.

Suherlan, 2001. Zonasi Tingkat Kerentangan Banjir Kabupaten Bandung Mengunakan System Informasi Geografis. (Skripsi). Bogor.
Kementrian Pekerjaan Umum, 2003. Pedoman Pengendalian Pemanfaatan Ruang Dikawasan Rawan Banjir. H. II-2.

Asdak, C. 2004. Hidrologi dan Pengelolaan Daerah Aliran Sungai. Cetakan Ketiga (revisi). Gadjah Mada University Press. Yogyakarta. Proses terjadinya infiltrasi.

Kodoatie, Robert J. \& Sugiyanto. 2002 "Banjir" Beberapa Penyebab dan Metode Pengendaliannya dalam Perspektif Lingkungan. Pustaka Pelajar: Yogyakarta,

Ditjen Penataan Ruang Dept. PU. 2015. Pedoman Pengendalian Pemanfaatan Ruang di Kawasan Rawan Bencana Banjir.

Yalcin dan Akyure. 2004. Menentukan Wilayah Rawan Banjir.

BPBD Kabupaten Bone, 2016. Kawasan Banjir Kab. Bone. 